\title{
Moving Toward Patient-Centered Care: Women's Decisions, Perceptions, and Experiences of the Induction of Labor Process
}

\author{
Jennifer E. Moore, PhD, RN, Lisa Kane Low, PhD, CNM, FACNM, \\ Marita G. Titler, PhD, RN, FAAN, Vanessa K. Dalton, MD, MPH, \\ and Carolyn M. Sampselle, PhD, RN, FAAN
}

\begin{abstract}
Background: Patient preferences and clinician practices are possible causative factors to explain the increase in induction of labor, but scientific studies that demonstrate this link are limited. The purpose of this study is to identify factors that influence inductions from the perspective of women. Methods: A qualitative investigation using grounded theory methodology was conducted. Women were interviewed preinduction and postinduction. Analysis of the interviews was conducted using constant comparison to identify codes, categories, and themes. Through this process the complex intersection between women, their clinician, and the application of evidence-based care in clinical practice was explored. Results: Five major themes from the preinduction interview were identified; safety of baby, women's trust in their clinician, relief of discomfort and/or anxiety, diminish potential or actual risk, and lack of informed decision making. Five major themes were identified from the postinduction interview; lack of informed decision making, induction as part of a checklist, women's trust in their clinician, happy with induction, and opportunities to improve the experience. Conclusions: Lack of informed decision making was cited as a barrier to optimal care. This study has important implications for patient-centered research and clinical care, requiring the inclusion of women and the salient concepts of care that they identify. (BIRTH 41:2 June 2014)
\end{abstract}

Key words: implementation science, induction of labor, informed shared decision making, patient-centered outcomes research

Despite evidence that elective induction of labor (IOL) increases health risks to mothers and their newborns, the rates of induction continue to rise (1-4) reaching 22.8 percent for all births in the United States in 2007 (3).
Experts speculate that the increase is attributable to the rising practice of elective IOL, which is associated with increased risk, particularly to the newborn when conducted before 39 weeks' gestation $(5,6)$. Elective IOL is
Jennifer E. Moore is a Patient-Centered Outcomes Research Fellow through the U.S. Department of Health and Human Services at the Agency for Healthcare Research and Quality, Rockville, Maryland, USA. Lisa Kane Low is an Associate Professor and Midwifery Program Coordinator at the University of Michigan School of Nursing, Ann Arbor, MI, USA. Marita Titler is an Associate Dean, Professor, and Division Chair at the University of Michigan School of Nursing, Ann Arbor, MI, USA. Vanessa Dalton is an Associate Professor of Obstetrics and Gynecology at the University of Michigan Medical School, Ann Arbor, MI, USA. Carolyn Sampselle is a Professor and Director of Community Engagement at the University of Michigan School of Nursing, Ann Arbor, MI, USA.
Address correspondence to Jennifer E. Moore, PhD, RN, Agency for Healthcare Research and Quality, 540 Gaither Road, Rockville, MD, USA, 20850.

Accepted October 30, 2013

(C) 2014 Wiley Periodicals, Inc. 
believed to be partially responsible for the recent increase in late preterm births and cesarean sections $(1,4)$. Patient preferences and clinician practices are the most commonly cited causative factors (7). However, investigations from the patient perspective are noticeably absent. There exists a need to understand how clinicians and women determine that IOL is desired. Any effort to decrease the rate of elective IOL hinges on the understanding of the factors that influence the use of this practice. Therefore, the purpose of this study is to identify factors that influence pregnant women's decisions about IOL, including their knowledge and understanding of the risks and benefits, and to explore postpartum women's experience of IOL. Use of a patient-centered approach to explore the practice of IOL is aligned with the national agenda of the Patient-Centered Outcomes Research Institute (8) and addresses recommendations from the U.S. Agency for Healthcare Research and Quality (5) to better understand IOL from the perspective of women.

\section{Methods}

Grounded theory methods guided this study's design and analysis, providing a framework for capturing the voices of women $(9,10)$. After institutional review board approval, all women enrolled in prenatal care at an academic medical center received a letter indicating they may be contacted by the research team if they were scheduled for an IOL. Using the following inclusion criteria, a purposeful sample was recruited: English-speaking, primiparous women, 21 years of age or older, scheduled for an IOL between December 2011 and February 2012, and between 34 and 41 weeks' gestation. As highlighted by recent evidence reviews $(5,11,12)$, all women who were scheduled for an IOL were included in the initial sampling frame as a result of the ambiguous boundaries between types of IOL (medical, indications with limited current evidence, and elective). Multiparous women were excluded from this study to eliminate the influence of previous stressful or unsatisfactory birth experiences (13).

A total of 101 women were scheduled to be induced during the study time period with 66 percent of the inductions representing either elective or indications that had limited evidence. Forty women were eligible for recruitment and 75 percent agreed to enroll (Table 1). At the request of her husband, one woman elected to leave the study after the data were collected. Saturation was suspected after 16 interviews; however, data collection continued to ensure that the phenomenon was fully explored. The sample was aligned with the national United States demographics of women who are induced (14-17).

\section{Procedures}

Women were contacted by phone within 6 hours of scheduling the induction to ensure accuracy in the recall of the discussion (18). If the woman met the inclusion criteria and agreed to participate, she was enrolled. The call continued with three preinduction interview questions (Table 2). Women were scheduled for a postinduction interview (Table 2) 4 weeks after their scheduled IOL. Each interview concluded by providing women with an opportunity to summarize their top three key points from the discussion. This approach ensured women's main points were accurately recorded and that false perceptions or inaccurate conclusions by the interviewer were not introduced.

Table 1. Demographics of Enrolled Women $(n=29)$

\begin{tabular}{|c|c|c|}
\hline \multicolumn{3}{|l|}{ Age, years } \\
\hline Mean & 30.2 & \\
\hline \multirow[t]{2}{*}{ Range } & $21-41$ & \\
\hline & $n$ & $\%$ \\
\hline \multicolumn{3}{|l|}{ Race* } \\
\hline White & 20 & 70 \\
\hline Black & 4 & 14 \\
\hline Asian & 2 & 7 \\
\hline American Indian & 1 & 3 \\
\hline Indian & 1 & 3 \\
\hline Arab/Middle Eastern & 1 & 3 \\
\hline \multicolumn{3}{|l|}{ Level of education } \\
\hline High school & 8 & 28 \\
\hline Vocational & 3 & 10 \\
\hline Associate & 1 & 3 \\
\hline Bachelor's & 7 & 24 \\
\hline Master's & 6 & 21 \\
\hline Doctorate & 4 & 14 \\
\hline \multicolumn{3}{|l|}{ Insurance coverage } \\
\hline Commercial & 17 & 59 \\
\hline Medicaid & 11 & 38 \\
\hline Military & 1 & 3 \\
\hline \multicolumn{3}{|l|}{ Clinician office location } \\
\hline \multicolumn{3}{|l|}{ (Type of clinicians at Location) } \\
\hline Office \#1 (OB Only) & 3 & 10 \\
\hline Office \#2 (OB and CNM) & 6 & 21 \\
\hline Office \#3 (OB and CNM) & 3 & 10 \\
\hline Office \#4 (OB, CNM, and NP) & 2 & 7 \\
\hline Office \#5 (Family MD only) & 1 & 3 \\
\hline Office \#6 (OB Residents only) & 12 & 42 \\
\hline Office \#7 (OB and CNM) & 2 & 7 \\
\hline Office \#8 (CNM only) & 0 & 0 \\
\hline
\end{tabular}

*Self-identified, preferred racial identity of women. $O B=$ obstetricians; $C N M=$ certified nurse-midwives; $N P=$ women's health nurse practitioners; Family $M D=$ family practice physicians; $O B$ Resident = obstetrician residents. 
The qualitative technique of member checking was conducted to validate data, analytic categories, interpretations, and conclusions (10). During the interviews, the researcher restated or summarized information and asked the woman to determine the accuracy of the statement. The information collected from each interview was immediately transcribed verbatim, reviewed, and compared with the other interviews. Medical records were reviewed to collect information about the reason for the IOL as documented by the clinician and to provide context of the pregnancy, labor, delivery, and postpartum period from a medical perspective.

\section{Data Analysis}

Data were analyzed using the constant comparison method with three levels of coding (19). First, data collected from each individual interview underwent open coding (Level I) consisting of sentence-by-sentence examination with substantive codes assigned. Codes that were similar were clustered into concepts. As these codes clustered they were assigned to categories (Level II). The categories were composed of coded data that formed patterns and were compared with other categories to ensure they were mutually exclusive (9). Categories were compared to determine fit within a higher-order category (Level III coding) to identify the thematic codes (Table 3). The preinduction and postinduction interview data for each woman were coded independently and compared. Once both interviews underwent Level II coding, they were compared to identify any similarities or differences between the two points in time in which information was collected about the woman's IOL. Standard techniques to ensure credibility of the analysis included use of peer debriefing and research team meetings to confirm consensus in the analysis process.

\section{Results}

\section{Preinduction Interview Results}

During the preinduction interview, women reported conversations about how IOL was initiated (clinician initiated or patient initiated). Women described their conversations for IOL as having minimal dialogue with their clinician. Women would ask for an IOL and their

Table 2. Examples of Interview Questions and Probes

Examples of interview questions

Examples of probes

\section{Preinduction interview}

Tell me about how the decision was made to be induced.

Share with me what was most important to you in making your decision to be induced.

When you think about your upcoming IOL, what things are you thinking about?

\section{Postinduction interview}

Tell me about your birth experience.

Reflecting back over your birth experience, please tell me more about how being induced did or did not impact your birth experience.

When you think back to when the decision was made to be induced, how do you feel about the decision to be induced?

Why do you think other women decide to be induced?

What would you want other women to know about if they were scheduled to be induced?

Now that you have experienced an IOL, what should health care providers tell women in preparation for the induction?

Based on the information that you have shared, tell me what you believe are the three most important "take away" messages of your IOL experience.
Tell me more about the conversation with your clinician about scheduling your induction.

Tell me more about what was particularly, if anything, important to you in making the decision.

Tell me about your expectations for the IOL.

Share with me what you expected and didn't expect about your birth experience.

Tell me more about the benefits and risks of being induced as it relates to your experience.

Tell me more about whether or not you felt prepared for the induction.

Tell me about how your friends or family may or may not have influenced your decision.

Tell me about how best to communicate with women information about the risks and benefits of being induced.

Share with me what information health care providers should tell women about the risks and benefits of being induced. 
Table 3. Linkage between Narratives, Level II Categories, and Level III Major Themes

Example of narrative passages from preinduction interview

You know, I know that there are risks if I am induced but I also know that it is better to be induced than to cause harm to my baby. She (physician) said it is better to be induced before 39 weeks for the safety of the baby. I don't want anything to happen to my baby. I feel like it is the right thing to do.

My doctor brought it up and said that she thought it would probably be a good idea. That was kind of like, what sold me on it. Completely. Her professional opinion.

I wish that it could happen sooner. I am just done being pregnant. I know that sounds terrible. You know, the fact that we know that she is growing fine, I am ready. It is time. I did ask if it could be earlier and she said no I cannot do it until 38 weeks. I am just uncomfortable which, unfortunately, is not a reason to do an induction. I am disappointed about that.

When they said that since I am already dilated to $2 \mathrm{~cm}$ and that she should react pretty good to the pitocin, I wasn't worried about the cesarean section. I am already dilated and she is doing good and doing what she is supposed to be doing so I feel OK about the risks.

Essentially, she just scheduled it and didn't ask us about whether we wanted it or not. It was her decision. Basically, she just said that she doesn't want me to go past 38 weeks because I have twins. She wanted to schedule it. She said things can happen with the babies. That is it...nothing more was said.
Factors that influence IOL, conversation to schedule IOL, benefits of IOL, feelings about decision, helpful information, sources of evidence, understanding of evidence

Factors that influence IOL, sources of evidence, conversation to schedule IOL, feelings about decision, helpful information, sources of evidence

Benefits of IOL, feelings about decision, thoughts about upcoming IOL, factors that influence

Conversation to schedule IOL, risks of IOL, sources of evidence, understanding of evidence

Conversation to schedule IOL, benefits of IOL, risks of IOL, helpful information, sources of evidence, understanding of evidence
Level III major theme

Safety of baby

Women's trust in their clinicians

Relief of discomfort and/or anxiety

Diminished potential or actual risks

Lack of informed decision making
Example of narrative passages from postinduction interview

I really didn't have all of the information when I scheduled the induction. I don't feel like I got a lot of education on it beforehand. You know, I got one paper before I went to the hospital. I don't think it had a lot of information. I mean, the paper just tells you the date of the IOL, to call the triage nurse, and where to go. I really was surprised by everything involved with the induction.

Induction should not be treated as a protocol or a checklist. It isn't just a simple step. Women need to be provided with information. They need to make an informed decision, give informed consent. The process currently treats it like scheduling an ultrasound but it is far from a simple ultrasound. There are risks and options that women should know before agreeing to it.

I trusted my doctor. I trusted my doctor and the hospital to do the right thing and to tell me the correct information that was best for me and my baby. He usually was good with providing information. Not sure why he didn't for the induction.

I was just ready for him to be born. I was uncomfortable. He might have been comfortable, but we were ready for him to be born. I didn't want to wait. I still feel like I would have done it again. It was the right thing to do because I was having pain and it just wasn't manageable.
Level II categories

Level III major theme

Decision of IOL, unprepared for IOL, unexpected from birth experience, not informed

Lack of informed decision making

Other women should know, information should have received, providers should tell women, IOL checklist

Decision of IOL, didn't know what they didn't know, trust provider

Women's trust in their provider

Birth experience, benefits of IOL, decision of IOL, factors that influence
IOL as part of checklist

Happy with IOL decision 
Table 3 Continued

\begin{tabular}{lcc}
\hline Example of narrative passages from postinduction interview & Level II categories & $\begin{array}{c}\text { Level III major } \\
\text { theme }\end{array}$ \\
\hline $\begin{array}{l}\text { I want my provider to explain it to me and give me a handout } \\
\text { but not when I am at the hospital 2 seconds away from } \\
\text { being induced. I mean, they explain it at the hospital but I } \\
\text { really didn't process it and I didn't look at the piece of paper. }\end{array}$ & $\begin{array}{c}\text { Decision of IOL, information should } \\
\text { have received, other women should } \\
\text { know, best way to communicate } \\
\text { benefits and risks, providers } \\
\text { should tell women }\end{array}$ & $\begin{array}{c}\text { Opportunities to } \\
\text { improve the } \\
\text { experience of } \\
\text { the IOL process }\end{array}$ \\
$\begin{array}{l}\text { ins and outs of the induction a couple of times before I am } \\
\text { even at the hospital, before I even make a decision. }\end{array}$ & \\
That would be nice.
\end{tabular}

clinician would agree to schedule it without discussion or resistance.

I just asked him when I was going to get induced and if it could be before 40 weeks...he opened up the calendar, showed it to me, and said, "pick a date that works for you."

Women generally described the encounter as brief without opportunities to ask questions or express concerns.

Five major themes (Table 3) emerged from the preinduction interview data: 1) safety of baby, 2) women's trust in their clinician, 3) relief of discomfort and/or anxiety, 4) diminished potential or actual risks, and 5) lack of informed decision making.

\section{Major Theme I: Safety of Baby}

Clinician-initiated IOL conversations focused on the clinician's rationale for the IOL and the potential risk to the baby if the induction was not carried out. Half of the participants noted that their clinician brought up safety of the baby as one of the reasons for the IOL. The safety of the baby was typically the main point that women identified when describing their conversation with their clinician. As an example, a 33-year-old woman stated:

\footnotetext{
He said to me that at 39 weeks the baby has reached all of the benefits from being inside of me. And then he told me that he would feel comfortable inducing me because of the potential problems with blood pressure harming my baby. $\mathrm{He}$ thought that it would be necessary to induce so it wouldn't become an emergent situation. But I felt, like, rushed. And I didn't feel like I had enough time to think through it. And I couldn't ask the questions that I knew that would come but I don't want to put my baby at risk.
}

For women who were unsure of the IOL, when safety of the baby was mentioned they agreed with the clinician's decision to be induced. Discussing safety of the baby limited further conversation or questions by women about the appropriateness of the IOL. After reviewing the medical records of the participants, only one IOL had documentation indicating a potential risk to the baby. The other 28 inductions did not have a documented medical issue or concern for the baby. Although a risk was not documented, it does not indicate that an actual or potential risk was not of concern to the clinician.

\section{Major Theme II: Women's Trust in their Clinician}

Women consistently identified that they trusted the information and rationale that their clinician presented and cited trust as the most important element in their agreement to be induced. The rationale presented by the clinician was further justified by the idea that the safety of the baby was in jeopardy if they did not proceed with the induction. Other sources of information (e.g., friends) were considered secondary to the expertise and recommendation of their clinician.

A 33-year-old woman who was induced for macrosomia stated:

Basically, my doctor said that 38 weeks is full-term and the baby is ready to come to the world. She said, "Don't worry about it. You don't want a big baby." I feel pretty comfortable with that answer. I trust her.

\section{Major Theme III: Relief of Discomfort and/or Anxiety}

Although a clinician's recommendation and safety of the baby influenced a woman's agreement for an IOL, women stated that they were happy with their clinician's recommendation to be induced. They explained that the IOL provided relief from the discomforts of pregnancy and/or anxiety related to not knowing when or where labor would begin. Regardless of whether the IOL was clinician- or patient-initiated, almost every woman expressed these feelings. 
There is a lot of built-in anxiety especially as a first-time mother and not knowing what to expect. Now I have more control over my birth because I know when it will happen and I will be at the hospital when it starts. Plus, I am so uncomfortable.

\section{Major Theme IV: Diminished Potential or Actual Risks of IOL}

During the interviews, women had difficulty identifying the risks associated with being induced. They shared the rationale their clinician discussed with them and the benefit of being induced (e.g., reduce discomfort) but they were unsure of the risks. Whether they were aware of the risks or not, the women diminished the actual or potential risk. They focused only on the elements that were most salient to them, such as relieving discomfort.

I am apprehensive about the induction because of the risks, but I am miserable and so uncomfortable. I can't breathe. Thirty-seven weeks is long enough.

\section{Major Theme V: Lack of Informed Decision Making}

Overall, most women were unable to describe the process, medications used, risks, or options associated with an IOL. For those women who did have some information, it was on the logistics of the IOL and not on the risks.

My doctor basically scheduled me to be induced tomorrow (38 weeks) but they will call me today to let me know what time they want me to go in. So, I know about what is going to happen. You know, about how I have to go through triage and how they are going to take me to my room and when I $\mathrm{am}$ in the room they are going to set-up IVs in case I need them and they will do blood testing.

However, women indicated that they wanted more information. To further explore women's contrasting thoughts about feeling informed but wanting more information, they were asked to identify what they would like to receive. Women identified a desire for general information and specific details about the process, medications used, the risks and benefits involved, and options.

\section{Postinduction Interview Results}

The postinduction interviews explored postpartum women's experiences of having an IOL. Five major themes (Table 3) emerged from the data: 1) lack of informed decision making, 2) IOL as part of a checklist, 3) women's trust in their clinician, 4) happy with IOL decision, and 5) opportunities to improve the experience of the IOL process.

\section{Major Theme I: Lack of Informed Decision Making}

Women began the conversation about their experience with the IOL process by identifying information that wasn't shared with them before the IOL. For instance, most women were not informed about the risk of cesarean section until after they had been admitted to the hospital. The risk of and subsequent need for a cesarean section associated with an IOL was a surprising and emotional event for women.

The c-section, I didn't expect that. No one told me about that. [crying]. I mean, that was something that was unexpected. This is hard to talk about. No one told me about it. I didn't want a cesarean section.

As women continued to discuss their IOL experience and the unexpected events that occurred (i.e., pain intensity, impact on baby, no eating, limited mobility, and increased risk of cesarean section), it became apparent that these items were not explained before the IOL. Instead, women were informed about the medications, the logistics, risks, and options after they had arrived at the hospital for their scheduled IOL (Table 4). A 33-year-old attorney, familiar with the concept of informed decision making, was emotionally passionate when describing her perception of the decision-making process.

\footnotetext{
I hate to say it but the induction was kind of a nondecision. We were led to believe that the induction was what was needed to prevent risks to him because I was getting close to my due date. We were basically told that this is when the induction was going to happen. We were not presented with all of the information about the risks or the options. We were not informed and therefore we were not making a decision. It is not a decision if you are not informed. You are just simply going along with what your doctor tells you.
}

Women who requested an elective IOL also realized they were not fully informed by their clinician. After reflecting on their IOL, they expressed that they were not prepared for the IOL.

Table 4. Comparison of Information Presented by Clinician and Nurse

\begin{tabular}{ll}
\hline $\begin{array}{l}\text { Information from } \\
\text { clinician in office }\end{array}$ & \multicolumn{1}{c}{$\begin{array}{c}\text { Information from } \\
R N \text { in the hospital }\end{array}$} \\
\hline Rationale for induction & Types of medications and risks \\
Safety of baby & Process and steps of IOL \\
Logistics (i.e., day and & Timeframe for an IOL \\
time of IOL) & Risks associated with IOL \\
& Restrictions (i.e., can't eat, \\
& limited mobility, no water birth) \\
\hline
\end{tabular}


I don't feel like I got a lot of education on it beforehand. You know, I got one paper before I went to the hospital. I don't think I had a lot of information.

\section{Major Theme II: IOL as Part of a Checklist}

Women were told that the IOL was needed or recommended with no or minimal information being presented about the process, risks, or options. Women would agree and then it was scheduled. It was treated as the natural next step in the woman's pregnancy, as part of a checklist of normal pregnancy.

You know, they don't give you time to think about it or consider it. They don't go into details about it. They don't give you a say in it because they push it so hard because it is part of their checklist. But you are at the end of your pregnancy and are uncomfortable so you just agree. You are ready to be done; you just want your baby. So, you don't question it, you trust your doctor.

\section{Major Theme III: Women's Trust in their Clinician}

Women indicated that despite feeling that they did not have enough information about the IOL, they did not seek out this information because they trusted their clinician and their concern for the safety of the baby. During the interview, women questioned why they did not seek this information from their clinician. A 41-year-old woman concluded that clinicians need to assume women know nothing because they have never done this before and that women do not know what questions to ask to ensure that they are informed.

I mean, I have no idea what to ask, no clue what to ask. Don't ask me if I have questions because I don't know what questions to ask. Just tell me the information because I don't know any of it.

\section{Major Theme IV: Happy with IOL Decision}

With the exception of a few women, women felt that the IOL was the right decision. They framed their satisfaction with the decision within the context of the benefits (e.g., reducing anxiety).

I look back and it's positive. Even with the decels, even with everything else, because she came out healthy. We prevented harm to her by being induced. Safety was an issue.

Three women reflected on their experience and the lack of information that was presented to them and concluded that the IOL was not appropriate. A woman induced at 39 weeks for macrosomia stated:

I think based on the information that we were given by my doctor, it was the right decision but he wasn't a big baby... the induction wasn't necessary.

\section{Major Theme V: Opportunities to Improve the Experience of the IOL Process}

Finally, as part of the postinduction interview, women felt strongly that other women should be informed about an IOL before making a decision. Consensus existed that women should know about the IOL process, medications, risks, and options as part of the decision-making process. A teary general surgeon compared her personal approach to discussing care with patients to what she had experienced.

\begin{abstract}
Women need to know the risks and benefits of doing something and the risks and benefits of not doing something. Once you have that information, then I feel that women can make their own decision. They can decide which option is more beneficial or riskier. I provide this type of information to my patients in advance so that they can make a decision that is best for them [crying]. I give them the time needed to think about it based on all of the information about the risks and benefits. After the decision is made to proceed, then it [information] is repeated with the nurse at the hospital. This should be done with inductions too. I don't see why not.
\end{abstract}

As a scheduled IOL is planned and not considered an urgent event, women indicated they wanted information well in advance as part of their conversation with their clinician before any decision is made.

A common recommendation from the interviews was that childbirth classes represent an opportunity to inform women about an induction. This idea was expressed by both women who did and did not attend childbirth education classes; about half of the women (48\%) in this study participated in some type of class. One woman started to cry when she offered what childbirth classes should tell women.

Well, I think in those classes, they really should tell you, they should say, like, you have the right to say no. You have the right, you know what I mean? You get to decide. You can choose. You can review the risks and ask questions and you can be the one to decide. Because, I think a lot of times the doctor just tells you some information and then they proceed forward. No one tells you that you can say no and that it is OK to say no.

Most women who did not attend a childbirth education class shared that it was because of scheduling conflicts or because it cost too much money. However, they indicated that all women should have access to a class and clinicians should encourage women to attend them.

\section{Discussion of Findings}

The major themes from the interviews provide insight from the perspective of women about the complex factors that influence the decisions to proceed with an IOL. The way in which a clinician frames the information, 
referred to as the "framing effect," influences women's decisions (20-24). Safety of the baby served as the critical piece of information, convincing women that an induction was necessary. The desire to have relief from discomfort and to alleviate anxiety associated with the unknowns of labor was a major theme also influencing women to proceed with IOL.

Participants trusted their clinician and their expertise, fueling agreement for IOL. This finding is consistent with results from the Simpson and colleagues $(25,26)$ study that found a physician offering an IOL was a strong predictor women would agree to be induced. The Listening to Mothers III survey (27) also found clinicians were a common source of reliable information for women when deciding on an IOL.

Women were given limited information about the process, medications, risks, or options. Although women desired more information, it is not known whether more information from their clinician would have altered their agreement to be induced. However, without this information, women did not have the opportunity for an informed discussion with their clinician or to be engaged in the decision-making process. This finding is consistent with the Listening to Mothers II survey (28) that found women chose IOL without adequate knowledge of the potential risks. Similar to the findings in this investigation, Emmett and colleagues (29) found clinicians focused primarily on procedural issues as opposed to risks and benefits when talking to women about a cesarean section.

Women in this study focused on the excitement of seeing their baby and relieving their discomfort and anxiety. Consistent with findings from Declerq and colleagues $(27,28)$, "get pregnancy over" and "control the timing of birth" were common reasons women identified to be induced. Furthermore, women in this study felt strongly that other women should be fully informed before making a decision. This finding is consistent with results from the Listening to Mothers surveys, in which women indicated that they wanted information about potential risks of IOL $(27,28)$. Regardless of whether a woman is induced for medical or elective reasons, she should always be informed and engaged in the decision-making process. As described by ACOG's Committee on Ethics (30), informed consent for medical treatment is an ethical requirement. Furthermore, informed consent should not be delayed until after being admitted to the hospital for the procedure. Receiving pivotal information about IOL at this stage is arguably too late to change the plan of care.

\section{Strengths and Limitations}

The primary strength of this study was the use of qualitative methods to understand women's perspective of the factors that influence decisions for IOL. This study is the first one in which the researchers are aware of or focused on factors that influence IOL from the perspective of women, both preinduction and postinduction. The study was conducted in a single health care system in the United States and relies on English-speaking participants, limiting generalizability. However, the site serves a diverse population of women, and 75 percent of eligible women enrolled during the recruitment period. Finally, the perspective of clinicians was not part of the study; therefore, it is not known whether clinicians, for instance, were following a checklist as women had described.

\section{Conclusion}

The findings from the study highlight the complex and sometimes conflicting factors that influence IOL. Women appear to be influenced by their clinician's rationale and emphasis on the safety of their baby. However, as an underlying factor, women's own desires to end discomfort and relieve anxiety of the unknown also influence their agreement to be induced. Patientinitiated inductions occurred without challenge or discussion about the risks from their clinician. For both patient- and clinician-initiated inductions, clinicians assumed an authoritative role in which women were not active participants in their care. DeVries and colleagues (31) found that women tend to favor the care that they are offered by their clinician. Women have a tendency, for many reasons, to avoid challenging the recommendation from their clinician despite not fully understanding the rationale. To address the increasing rates of IOL and its associated risks, informed, shared decision making should be encouraged as a first step.

\section{Disclaimer}

The views expressed in this article are those of the authors and do not necessarily reflect the position or policy of the U.S. Department of Health and Human Services or the Agency for Healthcare Research and Quality.

\section{Funding}

National Institutes of Health Individual National Research Service Award, Grant \#F31NR012855 (PI: Moore), and the Blue Cross Blue Shield Foundation of Michigan Dissertation Grant, Grant \#1808.SAP (PI: Moore). 


\section{Acknowledgments}

Thanks are due to the women who agreed to participate in this study by sharing their birth experiences and to Misty Muldowney for inspiring the development of this project. The authors also thank Deborah Oakley, PhD, $\mathrm{MPH}$, for providing her insight and expertise throughout the research process. Finally, the primary author would like to thank her colleagues at AHRQ for their thoughtful review and comments on the manuscript.

\section{References}

1. Ehrenthal DB, Jiang X, Strobino DM. Labor induction and the risk of a cesarean delivery among nulliparous women at term. Obstet Gynecol 2010;116(1):35-42.

2. Kaufman KE, Balit JL, Grobman W. Elective induction: An analysis of economic and health consequences. Am J Obstet Gynecol 2002;187(4):858-863.

3. Martin JA, Hamilton BE, Sutton PD, et al. Births: Final data for 2007. Hyattsville, MD: National Center for Health Statistics, 2010. Accessed July 8, 2012. Available at: http://www.cdc.gov/ nchs/data/nvsr/nvsr58/nvsr58_24.pdf.

4. Vardo JH, Thornburg LL, Glantz JC. Maternal and neonatal morbidity among nulliparous women undergoing elective induction of labor. J Reprod Med 2011;56(1-2):25-30.

5. Caughey AB, Sundaram V, Kaimal AJ, et al. Evidence report: Maternal and neonatal outcomes of elective induction of labor. Evidence Report/TechnologyAssessment No. 176. Rockville, MD.: Agency for Healthcare Research and Quality; 2009. Accessed December 16, 2009. Available at: Ihttp://www.ahrq.gov/ downloads/pub/evidence/pdf/elindlabor/eilabr.pdf.

6. Oshiro BT, Henry E, Wilson J, et al. Decreasing elective deliveries before 39 weeks of gestation in an integrated health care system. Obstet Gynecol 2009;113(4):804-811.

7. Moore JE, Low LK. Factors that influence the practice of elective induction of labor: What does the evidence tell us? J Perinat Neonatal Nurs 2012;26(3):1-9.

8. Fleurence R, Selby JV, Odom-Walker K, et al. How the patientcentered outcomes research institute is engaging patients and others in shaping its research agenda. Health Aff (Millwood) 2013;32(2):393-400.

9. Glaser B. Theoretical Sensitivity. Mill Valley, CA: The Sociology Press, 1978.

10. Lincoln Y, Guba E. Naturalistic Inquiry. Thousand Oaks, CA: Sage, 1985.

11. Mozurkewich E, Chilimigras J, Koepke E, et al. Indications for induction of labour: A best-evidence review. BJOG 2009;116(5): 626-636.

12. World Health Organization. WHO recommendations for induction of labour. Geneva, Switzerland: WHO Press; 2011. Accessed January 13, 2012. Available at: ไhttp://whqlibdoc.who. int/publications/2011/9789241501156_eng.pdf.

13. Moffat MA, Bell JS, Porter MA, et al. Decision making about mode of delivery among pregnant women who have previously had a caesarean section: A qualitative study. BJOG 2006; 114(1):86-93.

14. Coonrod DV, Bay RC, Kishi GY. The epidemiology of labor induction: Arizona 1997. Am J Obstet Gynecol 2000;182 (6):1355-1361.

15. Dublin S, LydonRochelle M, Kaplan RC, et al. Maternal and neonatal outcomes after induction of labor without an identified indication. Am J Obstet Gynecol 2000;183(4):986-994.

16. Glantz JC. Elective induction vs. spontaneous labor associations and outcomes. J Reprod Med 2005;50(4):235-240.

17. Murthy K, Grobman WA, Lee TA, Holl JL. Trends in induction of labor at early-term gestation. Am J Obstet Gynecol 2011; 204(5):435.e1-e6.

18. Baron J, Hershey JC. Outcome bias in decision evaluation. $J$ Pers Soc Psychol 1988;54(4):569-579.

19. Glaser B, Strauss A. Discovery of Grounded Theory: Strategies for Qualitative Research. Mill Valley, CA: The Sociology Press, 1967.

20. Kahneman D, Tversky A. Choices, values, and frames. Am Psychol 1984;39(4):341-350.

21. O'Connor AM, Pennie RA, Dales RE. Framing effects on expectations, decision, and side effects experienced: The case of the influenza immunization. J Clin Epidemiol 1996;49(11):1271-1276.

22. Payne JW. Information processing theory: Some concepts and methods applied to decision research. In: Wallsten TS, ed. Cognitive Processes in Choice and Decision Behavior. Hillsdale, NJ: Lawrence Earlbaum Associates, 1980:95-115.

23. Sullivan KE, Hebert PC, Logan J, et al. What do physicians tell patients with end-stage COPD about intubation and mechanical ventilation? Chest 1996;109(1):258-264.

24. Tversky A, Kahneman D. The framing of decisions and the psychology of choice. Science 1981;211(4481):453-458.

25. Simpson KR, Newman G, Chirino OR. Patient education to reduce elective inductions. MCN 2010;35(4):188-194.

26. Simpson KR, Newman G, Chirino OR. Patients' perspectives on the role of prepared childbirth education in decision making regarding elective labor induction. J Perinat Educ 2010;19(3): 21-32.

27. Declercq ER, Sakala C, Corry MP, et al. Listening to Mothers III: Pregnancy and Birth. New York: Childbirth Connection, 2013.

28. Declercq ER, Sakala C, Corry MA, Applebaum S. Listening to Mothers II: Report of the Second National U.S. Survey of Women's Childbearing Experiences. New York: Childbirth Connection, 2006.

29. Emmett CL, Shaw ARG, Montgomery AA, Murphy DJ. Women's experience of decision making about mode of delivery after a previous caesarean section: The role of health professionals and information about health risks. BJOG 2006;113(12):1438-1445.

30. ACOG Committee on Ethics. ACOG Committee Opinion No. 439: Informed Consent. Obstet Gynecol 2009;114(2):401-408.

31. DeVries R, Salvesen H, Wiegers T, Williams A. What (and why) do women want? The desires of women and the design of maternity care. In: DeVries R, Benoit C, van Teijlingen E, Wrede S, Eds. Birth by Design: Pregnancy, Maternity Care, and Midwifery in North America and Europe. New York: Routledge, 2001: 243-267. 